\title{
Exercise Therapy in the Management of Solid Tumors
}

\author{
Lee W. Jones, PhD, Jeffrey Peppercorn, MD, Jessica M. Scott, PhD, and Claudio Battaglini, \\ PhD \\ Duke University Medical Center, Box 3085, Durham, NC 27710, USA \\ Lee W. Jones: lee.w.jones@duke.edu
}

\begin{abstract}
Opinion statement

The benefits of exercise in patients with chronic disease have been studied extensively over the last half century. In contrast, investigation of the role of exercise following a diagnosis of cancer has received comparably less attention. In this article, we review the efficacy of exercise training in specific areas across the cancer survivorship continuum [i.e., pre-surgery, post-surgery during adjuvant therapy, following the completion of primary adjuvant therapy (survivorship), and palliation], with a view toward future research. The current evidence base provides strong but preliminary evidence that exercise training is a well-tolerated and safe adjunct therapy that can mitigate several common treatment-related side-effects among cancer patients with early disease both during and following adjuvant therapy although many questions remain unanswered. Preliminary evidence in this area supports that exercise therapy may be an important consideration in multidisciplinary management of patients following a cancer diagnosis.
\end{abstract}

\section{Introduction}

The therapeutic properties of regular exercise have long been recognized with the ancient Greeks and Chinese acknowledging the hygienic value of regular exercise. The first formal investigation was not until the early 1950s when James Morris and colleagues reported that occupational exercise was associated with substantial reductions in coronary heart disease in the seminal London Busmen study [1-3]. This pioneering study led to extensive epidemiological investigation of the association between both occupational and leisure-time exercise and the risk of cardiovascular disease by numerous research groups [4]. As a result of the burgeoning evidence, in 1995 the American College of Sports Medicine and Centers for Disease Control published the first prescription guidelines to encourage increased participation in exercise in Americans of all ages for health promotion and disease prevention [5]. The putative relationship between exercise and cancer was not formally recognized until 2002 wherein the American Cancer Society recommended regular exercise to reduce the risk of breast, colon, and several other forms of cancer [6].

Investigation of the role of exercise following a diagnosis of cancer has received comparably less attention. Following the diagnosis of other non-cancer chronic diseases, exercise therapy is considered the cornerstone of rehabilitation and demonstrated to improve quality of life and clinical outcomes in these settings. The precise reasons of why researchers and health professionals were more reluctant to investigate the therapeutic role of exercise following a diagnosis of cancer is not known but likely reflects the prevailing dogma that a cancer diagnosis is associated with poor prognosis, immune deficiency, and other severe

(C) Springer Science+Business Media, LLC 2010

Correspondence to: Lee W. Jones, lee.w. jones@duke.edu. 
debilitating side-effects that precludes participation in and benefit from exercise therapy. In the last decade, however, exercise-oncology research has become increasingly recognized as a legitimate and important field of research in cancer management [7]. This review will provide an overview of the putative evidence supporting the role of exercise across the cancer survivorship continuum (i.e., diagnosis to palliation).

\section{Exercise therapy following a cancer diagnosis}

\section{A brief history and overview}

- In the mid-to-late 1980s, researchers initiated the first studies to explore whether exercise training may be an appropriate intervention to mitigate chemotherapy- and radiation-induced fatigue and loss of cardiorespiratory fitness among women with early-stage breast cancer [8-13]. Since this early seminal study, the number of publications has steadily increased over the past 20 years with studies becoming progressively more sophisticated in scope, design, and size to address the major questions in the field [14]. A chronological time-line of significant landmarks in "exercise-oncology" research is presented in Fig. 1.

- Several excellent systematic reviews and meta-analyses have evaluated the pertinent literature [22-27]. In the most recent systematic review, Speck et al. [14]. identified a total of 66 "high quality" studies that examined the effects of exercise on 60 different physiological, functional, biological, or psycho-social outcomes in adults with cancer. In order to summarize, the majority of studies were conducted in women with early breast cancer with fewer studies in non-small lung cancer (NSCLC), hematologic malignancies, or mixed cancer populations. Exercise modality consisted of aerobic training alone, resistance training alone, or the combination of aerobic and resistance training prescribed at a moderate-vigorous intensity (50-75\% of baseline maximum heart rate or cardiorespiratory fitness), 3 sessions or more per week, for 10-60 min per exercise session. The length of the exercise training ranged from 2 to 24 weeks. Overall, exercise was associated with significant improvements in muscular strength, cardiorespiratory fitness, functional quality of life (QOL), fatigue, anxiety, and self-esteem. Few adverse events (AEs) were observed. It was concluded that exercise is a beneficial adjunct therapy both during and following the completion of adjuvant therapy in adult cancer patients, with low incidence of AEs [14]. Our group recently conducted a meta-analysis to determine the effects of supervised exercise training on cardiorespiratory fitness including only those studies employing a randomized controlled design and direct measurement of peak oxygen consumption $\left(\mathrm{VO}_{2 \text { peak }}\right)$, the gold standard assessment of cardiorespiratory fitness [28]. Cardiorespiratory fitness is determined by the integrative capacity of the cardiopulmonary system (i.e., pulmonary-cardiacvascular-skeletal muscle axis) to deliver oxygen from the atmosphere to muscle mitochondria [29•]. Cardiorespiratory fitness is one of the most powerful predictors of cardiovascular and all-cause mortality in healthy adults as well as those with cardiovascular disease (CVD) even after controlling for traditional CVD risk factors [30-34].

- In contrast to Speck et al. [14]. we only identified a total of 6 studies met eligibility criteria involving a total of 571 adult cancer patients ( $n=344$, exercise; $n=227$, usual care control). Pooled data indicated that exercise training was associated with a statistically significant increase in $\mathrm{VO}_{2 \text { peak }}\left(\mathrm{WMD}=2.91 \mathrm{~mL} \mathrm{~kg}^{-1} \mathrm{~min}^{-1}, 95 \%\right.$ CI: 1.18-4.64) with minimal adverse events, although significant heterogeneity was evident in this estimate $\left({ }^{2}=87 \%\right)$ [28]. We concluded that the effect of exercise on $\mathrm{VO}_{2 \text { peak }}$ is promising but the current evidence base is emergent with many fundamental questions ( $\mathrm{eg}$, optimal prescription, timing, and setting of exercise, 
effects of exercise on tumor biology and therapeutic efficacy) remaining to be addressed. In the following sections, we review the efficacy of exercise training in specific areas across the cancer survivorship continuum [i.e., presurgery, postsurgery during adjuvant therapy, survivorship (following the completion of primary adjuvant therapy), and palliation], with a view toward areas requiring future research.

\section{Exercise therapy prior to surgical resection}

- Surgery is the most common form of cancer therapy for patients with solid tumors. Of all cancer surgeries, only pulmonary resection for patients with lung cancer directly impacts an organ component that directly governs cardiorespiratory fitness (i.e., diffusion capacity) [29•]. Pulmonary resection is the treatment of choice for a variety of disorders including non-small cell lung cancer, selected cases of oligometastatic disease (sarcoma, colorectal cancer, melanoma, etc.) and involves removal of a substantial portion of lung parenchyma that negatively impacts pulmonary ventilation and diffusion capacities. In addition, the majority of lung cancer patients also present with several significant concomitant co-morbid diseases. The extent of surgery together with comorbid disease significantly complicates the treatment process and perioperative and postoperative complications are common; mortality and morbidity has been reported to range from $1 \%$ to $8 \%$ and $20 \%$ to $40 \%$, respectively [35-37]. In order to evaluate complication risk, cancer surgeons often assess $\mathrm{VO}_{2 \text { peak }}$ to determine preoperative physiologic status of operable candidates. $\mathrm{VO}_{2 \text { peak }}$ is strongly inversely associated with surgical complication rate in NSCLC patients [38-41]. Further, we found that $\mathrm{VO}_{2 \text { peak }}$ is also a strong independent predictor of long-term overall survival in NSCLC even after controlling for traditional prognostic factors [42••]. To date, the clinical importance of $\mathrm{VO}_{2 \text { peak }}$ has only been investigated in patients with NSCLC, however it appears reasonable to speculate that this parameter may also predict complication rate in other operable solid tumors particularly those associated with significant complications ( $e g$, bladder, colorectal). Given this, therapies that can augment $\mathrm{VO}_{2 \text { peak }}$ prior to surgical resection may lower perioperative complications and improve postsurgical recovery in cancer patients.

- To our knowledge, only two studies have investigated this question. Our group examined the efficacy of presurgical aerobic training on $\mathrm{VO}_{2 \text { peak }}$ among 20 patients with suspected NSCLC. Results indicated that mean $\mathrm{VO}_{2 \text { peak }}$ increased by $2.4 \mathrm{~mL}$ $\mathrm{kg}^{-1} \mathrm{~min}^{-1}$ from baseline to presurgery. Exploratory analyses indicated that presurgical $\mathrm{VO}_{2 \text { peak }}$ decreased postsurgery, but did not decrease beyond baseline values [43]. Similarly, Bobbio et al. [44]. reported that short-term exercise-based pulmonary rehabilitation increased $\mathrm{VO}_{2 \text { peak }}$ by $2.8 \mathrm{~mL} \mathrm{~kg}^{-1} \mathrm{~min}^{-1}$ prior to pulmonary resection in 12 NSCLC patients with chronic obstructive disease. These studies provide preliminary evidence that supervised pre-surgical exercise training can improve $\mathrm{VO}_{2 \text { peak }}$ although larger, randomized trials investigating the efficacy of exercise training on surgical complications and post-surgical recovery in cancer patients are now warranted.

- In addition to surgical complications and postoperative recovery, the presurgical setting also offers the unique opportunity to examine whether exercise training causes changes in tumor biology in vivo. Specifically, exercise interventions can be performed in cancer patients awaiting surgical resection (i.e., those not receiving cytotoxic therapy) as well as those receiving induction/neoadjuvant therapy. To our knowledge, no study has examined the effect of exercise on tumor outcomes in this setting. Such studies are likely to present a unique challenge since the time from 
initial cancer diagnosis to surgery is typically $<6$ weeks in most scenarios for patients not receiving preoperative therapy; $<6$ weeks may be an insufficient period of time in which to induce significant alterations in tumor biology/physiology [45]. In contrast, it is not possible to investigate the independent properties of exercise on tumor outcomes in those patients receiving preoperative therapy, although the period of time available for exercise is typically longer. Such barriers, however, are not insurmountable. Indeed, two dietary trials have demonstrated that flax seed supplementation and a low-fat diet, respectively caused significant changes in benign prostate proliferation and gene expression in men with prostate cancer awaiting radical prostatectomy $[46,47]$. The importance to conduct similar trials in exercise-oncology research can not be overstated. Information from such trials will provide molecular insight into how exercise may impact tumor biology which, in turn, will guide the development of mechanistically-driven trials to optimize the efficacy of exercise following a cancer diagnosis.

\section{Exercise therapy during adjuvant therapy}

- The use of anticancer therapies is associated with unique and varying degrees of direct and indirect physiological injury that dramatically reduce patients ability to tolerate exercise (i.e., low $\mathrm{VO}_{2 \text { peak }}$ ) predisposing to morbidity, poor psycho-social functioning, and increase susceptibility to concomitant age-related conditions [29•]. The effect of cancer therapy on $\mathrm{VO}_{2 \text { peak }}$ has been reviewed in detail previously. In the mid-to-late 1980s, researchers initiated the first studies to explore whether structured exercise training may be an appropriate intervention to mitigate chemotherapy- and radiation-induced toxicities and anticipated loss of cardiorespiratory fitness among women with early-stage breast cancer [8-13]. Since these early studies, more than half of the exercise studies in cancer patients have been conducted during cytotoxic therapy. Overall, the current evidence base provides promising evidence that exercise training is a well-tolerated and safe adjunct therapy that can mitigate several common treatmen-trelated side-effects among patients receiving polychemotherapy, locoregional radiation, and androgen deprivation therapy (ADT) [14, 28]. Results of these "first generation" studies provide a solid platform to launch "second generation" studies that will extend the scope and application of exercise-oncology research.

- A question of great interest is whether cancer patients are equally responsive to exercise training during cytotoxic therapy compared with following the completion of therapy. Results of our recent meta-analysis indicated that exercise training was associated with superior $\mathrm{VO}_{2 \text { peak }}$ improvements following compared to during adjuvant therapy, although no study has formally investigated this question [28]. In order to illustrate, in the largest study to date, Courneya et al. [20]. found that $\sim 17$ weeks of aerobic training did not improve $\mathrm{VO}_{2 \text { peak }}$ among women receiving anthracycline-containing chemotherapy for early breast cancer. Similarly, we found that 14 weeks of aerobic training led to negligible improvements in $\mathrm{VO}_{2 \text { peak }}$ among patients undergoing cisplatin-based adjuvant chemotherapy for early NSCLC [48]. It is also important to stress that although exercise training caused minimal improvements in $\mathrm{VO}_{2 \text { peak }}$, these effects occurred against the background of declines in $\mathrm{VO}_{2 \text { peak }}$ in patients assigned to the control condition; in the study by Courneya et al. [20]. $\mathrm{VO}_{2 \text { peak }}$ declined $\sim 5 \%$ among women randomized to usual care control. Intriguingly, several other studies have reported significant improvements in $\mathrm{VO}_{2 \text { peak }}$ and other pertinent outcomes in patients receiving other types of conventional cytotoxic therapies such as radiation and ADT [49-54]. These findings suggest that exercise-induced adaptations in the cardiopulmonary system may be contingent on the type of cytotoxic therapy being administered. In 
addition, the effects of exercise in patients receiving novel cytotoxic and cytostatic anticancer therapies are also needed. Such therapies have distinct mechanisms of action $[55,56]$ thus the exercise response in patients receiving these agents is also expected to be distinct. Further studies are now warranted to examine how different conventional and novel therapeutics influence exercise-induced alterations in the organ components that govern $\mathrm{VO}_{2 \text { peak }}$. Such mechanistic data will refine the optimal exercise prescription guidelines as well as inform novel combination approaches (eg, aerobic training plus pharmacologic intervention) to maximize $\mathrm{VO}_{2 \text { peak }}$ improvement in patients receiving anticancer therapy.

- The recent systematic review by Speck et al. reported that the effect of exercise in cancer patients has been evaluated across a total of 60 different outcomes [14]. However, the vast majority of studies have focused on the efficacy of exercise on measures of cardiorespiratory fitness, QOL, fatigue and body weight/composition with further studies investigating the effects on important biomarkers such as immune function and metabolic control. In the next generation of studies, it will be important to broaden the scope of exercise to other common toxicities observed during cytotoxic therapy; these include but are not limited to anemia, hypertension, neutropenia, peripheral neuropathy, and arthralgias. We also stress the importance of conducting hypothesis-driven parallel correlative science studies in such trials to provide insight into the mechanisms underlying the potential beneficial effects of exercise on these common toxicities.

- Another common toxicity for which exercise may be particularly effective is cardiotoxicity. Many chemotherapeutic agents used in cancer management are associated with unique acute and long-term cardiac complications [57]. While the majority of complications are transient effects that do not persist after completing chemotherapy, use of anthracycline-containing regimens (i.e., doxorubicin, epirubicin) is well recognized to trigger dose-dependent, cumulative, progressive cardiac dysfunction manifest as decreased left ventricular ejection fraction (LVEF), and ultimately, symptomatic congestive heart failure [58]. Older radiotherapy techniques independently cause a variety of cardiac complications and exacerbate chemotherapy-induced injury although newer techniques have considerably lower this risk $[59,60]$. Finally, the new arsenal of "targeted" cancer therapeutics is associated with a different safety profile than conventional approaches, however, it is apparent that these agents can cause damage to the heart. HER-2 directed agents as well as angiogenesis inhibitors are associated with a low incidence of subclinical and clinical left ventricular dysfunction which appears higher in those patients with prior or concurrent anthracycline administration [55, 56, 61]. The mechanisms of cancer therapy-induced cardiac dysfunction are not fully elucidated but exercise may be one therapeutic approach to prevent and/or mitigate this toxicity. In a series of preclinical studies, Hayward and colleagues [62-66] reported that both acute and chronic (repeated) moderate-intensity voluntary wheel exercise preserved cardiac function in mice receiving doxorubicin. In the only clinical study to date, Haykowsky et al. [67•]. found that exercise did not attenuate adjuvant trastuzumab-induced left ventricular dilation and reduced ejection fraction in 17 women with HER-2 positive early breast cancer, although adherence to the exercise intervention was less than optimal and no control group (i.e., trastuzumab- only) was included.

- Another major question to consider when investigating the effects of exercise training during cancer therapy but one that has received minimal attention is the potential interaction between exercise and cancer therapeutic efficacy [29•]. The potential interaction between exercise and cancer therapy efficacy is biologically 
plausible. Exercise is a potent pleiotropic intervention that influences a wide spectrum of biological processes that could potentially modulate the cytotoxicity of chemotherapeutic agents. For example, exercise modulates hormonal and metabolic profile, nitric oxide-mediated peripheral blood flow, angiogenesis, oxidative status, chemo-cytokine activity, immunity, and pharmacokinetic profile of agents [16•]. All these pathways are implicated in cancer therapeutic action and could, theoretically, augment or inhibit treatment efficacy. As an initial step, we investigated the effects of 8 weeks of forced treadmill running on the antitumor efficacy of doxorubicin in female mice bearing human breast cancer xenografts. We found no significant differences on tumor growth between groups receiving doxorubicin alone vs doxorubicin plus exercise training $(P=0.33)$, suggesting that exercise does not significantly modulate doxorubicin-induced tumor growth delay in MDA-MB-231 breast carcinoma xenografts [16•]. Nevertheless, this study has several limitations including the use of immune compromised mice and subcutaneous as opposed to an orthotopic breast cancer model. In a subsequent experiment, we found that tumor growth was comparable between voluntary wheel running and sedentary control in female mice orthotopically implanted with MDAMB- 231. Intriguingly however, tumors from exercising animals had significantly improved blood perfusion/vascularization relative to the sedentary control group suggesting that aerobic exercise can significantly increase intratumoral vascularization which may "normalize" the tumor microenvironment and, in turn, inhibit tumor cell meta-static dissemination and improve therapeutic efficacy [68]. Investigation of these intriguing questions is the subject of ongoing investigation in our laboratory.

\section{Exercise therapy following the completion of adjuvant therapy (survivorship)}

- Improvements in early detection and surveillance together with more effective locoregional and systemic therapies have led to significant survival gains for individuals diagnosed with cancer [69]. Indeed, approximately 12 million Americans who have been diagnosed with cancer are alive today. However, it is becoming increasingly apparent that improved outcomes in patients with earlystage disease may come at the price of therapy-induced late effects [70, 71]. As a result, there has been a significant paradigm shift toward long-term therapyassociated toxicity and its resultant effects on morbidity, premature non-cancer, competing causes of mortality, and QOL. Of importance, emerging evidence indicates $\mathrm{VO}_{2 \text { peak }}$ is centrally implicated in the etiology of certain cancer therapy late effects. The studies by our group, and by others found that $\mathrm{VO}_{2 \text { peak }}$ is a predictor of left ventricular function, cardiovascular disease risk factors ( $\mathrm{eg}$, blood pressure, lipid profile, c-reactive protein), as well as global QOL, fatigue, and other psycho-social outcomes in patients with solid malignancies. [41, 72-77] Exercise training is acknowledged as the most effective method to improve $\mathrm{VO}_{2 \text { peak }}$ in healthy adults and such improvements may, in turn, reverse certain therapy-late effects. Accordingly, there has been increasing clinical and research interest in the role of exercise in cancer survivorship [7]. Similar to during therapy, the current evidence base after the completion of primary adjuvant therapy indicates that exercise is a safe and well-tolerated therapy associated with significant improvements in certain physiological and psycho-social therapy late-effects. Again, several fundamental questions, however, remain to be addressed [14, 28].

- An important goal in exercise-oncology research is to identify the optimal exercise prescription in cancer survivors. Cancer is a heterogeneous disease varying considerably in location, pathogenesis, therapeutic management, and late effects. Thus, it seems reasonable to expect that these factors will alter the exercise 
response and, consequently, the exercise prescription. The vast majority of studies to date have investigated the effects of either aerobic training alone, resistance training alone, or the combination of aerobic and resistance training in accordance with traditional exercise prescription guidelines $\left(3-5 \mathrm{~d} \mathrm{wk}^{-1}\right.$ at $50 \%$ to $75 \%$ of baseline $\mathrm{VO}_{2 \text { peak }}$ for 12-15 weeks) in cancer survivors [14, 28]. As the field progresses, it will be important to conduct adequately powered studies that identify the optimal type, intensity, duration, and frequency of exercise training to improve symptom control in cancer survivors. At least three ongoing trials are addressing different aspects of this question in NSCLC [78], breast [79], and prostate cancer survivors [80]. Of particular interest is highintensity exercise training. Several recent randomized trials have demonstrated that the high-intensity aerobic training (i.e., $\geq 75 \%$ of baseline exercise capacity) causes superior improvements in $\mathrm{VO}_{2 \text { peak }}$ relative to low- or moderate-intensity exercise training in patients with or at risk of CVD [81-83]. However, there is a dearth of data regarding effects of exercise intensity following a cancer diagnosis [79].

- A major unanswered question, and one of considerable interest, is whether the benefits of physical activity extend beyond symptom control to improved survival following a cancer diagnosis [7]. The extant literature indicates that, in general, regular physical activity is associated with $15 \%$ to $61 \%$ reduction in the risk of death from breast or colorectal cancer (Table 1) [83-87]. Of interest, the association between physical activity and cancer-specific mortality is not uniform, which appears to vary according to volume of physical activity and even cancer type. In breast cancer, the amount of physical activity that was significantly inversely associated with cancer death ranged from $\geq 9$ MET-h wk ${ }^{-1}$ (brisk walking for $30 \mathrm{~min}, 5 \mathrm{~d} \mathrm{wk}^{-1}$ ) [83••] to $\geq 21 \mathrm{MET}$-h wk ${ }^{-1}$ (brisk walking for $75 \mathrm{~min}, 5 \mathrm{~d}$ $\mathrm{wk}^{-1}$ ); [88] in colorectal cancer; the range was $\geq 18$ MET-h wk ${ }^{-1}$ (brisk walking for $60 \mathrm{~min}, 5 \mathrm{~d} \mathrm{wk}^{-1}$ ) [86, 87] to $\geq 27$ MET-h wk ${ }^{-1}$ (brisk walking for $90 \mathrm{~min}, 5 \mathrm{~d}$ $\mathrm{wk}^{-1}$ ) [85]. Furthermore, the protective properties of physical activity appear more robust in patients with colorectal cancer than breast cancer. Finally, exploratory analyses indicate that the effects of physical activity may also differ by histological sub-type and tumor expression of certain molecular markers. First, Holmes et al. [17-•] reported that $\geq 9$ MET-h $\mathrm{wk}^{-1}$ was associated with a relative risk reduction in mortality of only $9 \%$ in women with estrogen receptor (ER)-negative tumors relative to a mortality reduction of $50 \%$ in women with ER-positive tumors. Similarly, Irwin et al. [89] found that women reporting $>0$ MET-h wk ${ }^{-1}$ had a mortality risk reduction of $80 \%$ in ER-positive patients relative to a $26 \%$ increase in ER-negative patients. Second, Meyerhardt et al. [18•, 21]. reported that the association between exercise and mortality in patients with stage I-III colon cancer may depend on p27 status. Specifically, tumors with loss of p27, the HR for colon cancer mortality was 1.40 (95\% CI, 0.41-4.72) for patients reporting $\geq 18$ MET-h $\mathrm{wk}^{-1}$ relative to those reporting $<18 \mathrm{MET}-\mathrm{h} \mathrm{wk}{ }^{-1}$. Conversely, tumors with expression of $\mathrm{p} 27$, the HR for colon cancer mortality was 0.33 (95\% CI, 0.12 0.85). Molecular status of fatty acid synthase, K-ras, p53, p21, and PI3KCA did not modify the association between exercise and clinical outcome.

- Together, these findings suggest that the responsive of primary tumors, the tumor microenvironment, or development of micrometastatic disease to physical activity may depend on tumor type and molecular status, exercise volume, and histological sub-type. The association between physical activity and death from any cause was more consistent. Nevertheless, the volume of physical activity required to obtain statistically significant reductions again differed between studies ranging from $\geq 9$ to $27 \mathrm{MET}-\mathrm{h} \mathrm{wk}{ }^{-1}$. Clearly, more studies are required to further investigate the 
association between post-diagnosis physical activity and clinical outcomes in breast and colorectal cancer as well as other cancer populations.

- To date, efforts to launch phase III-randomized trials of exercise on survival after a cancer diagnosis through the National Institutes of Health (NIH) have proven unsuccessful [93], but at least one trial is currently ongoing in Canada [18•]. Specifically, the Colon Health and Life-Long Exercise Change (CHALLENGE) trial is a phase III trial, investigating the effects of regular exercise on recurrence and cancer-specific mortality in colorectal cancer patients. The results of this trial are eagerly anticipated. In conjunction with such trials, parallel correlative science and translational studies are critical to understand the molecular underpinnings of therapeutic response to ensure the optimal safety and efficacy of exercise, and facilitate the shift toward "personalized medicine" in oncology [7].

\section{Exercise therapy in advanced (palliative) disease}

- Despite significant advances in diagnosis and management of earlystage disease, over 560,000 Americans are expected to die from cancer in 2010 [69]. Median survival of patients with advanced (inoperable) disease is heterogeneous and varies dramatically according to molecular subtype and response to therapy. Similar to patients with early disease, current therapeutic approaches in advanced disease are associated with a broad range of deleterious toxicities that negatively impact physical functioning leading to higher disease-related symptoms and impaired QOL. Given its incurable nature, treatment-related morbidity and QOL are becoming increasingly recognized as outcomes of major clinical importance in the management of advanced cancer. Exercise-oncology research is a new field; thus, it is logical that investigators have predominately focused on the role of exercise in patients with early-stage disease-patients, in general, with better physical functioning and prognosis, and experiencing less treatment-related toxicities. However, we contend that there is now sufficient evidence of the tolerability, safety, and preliminary efficacy of exercise in patients with early-stage disease to launch preliminary exercise investigations in select cancer sites with advanced disease.

- The conduct of exercise training interventions in patients with advanced disease represents a unique challenge relative to the clinical populations and settings where exercise trials have been traditionally conducted in oncology (i.e., early-stage disease) and other non-cancer clinical settings (eg, cardiovascular and respiratory disease). For example, patients with advanced disease, by definition, have systemic (metastatic) disease, have often been heavily pre-treated for prior early-stage disease, and are likely receiving aggressive combination cytotoxic and supportive care therapies. As such, these patients are likely experiencing more disease-related and treatment-related toxicities that may influence exercise tolerance and adherence. In conjunction, a high proportion of advanced disease patients present with a range of comorbid conditions related to prior cytotoxic therapy (for their previous diagnosis of early-stage disease) as well as common age-related disorders (eg, cardiovascular disease, osteoporosis, etc.) that may further negatively affect ability to engage in an exercise intervention and may increase the risk of an exercise-related AE [74, 94•].

- A recent systematic review by Lowe et al. [95]. identified a total of six studies that investigated the effect of an exercise intervention on QOL, fatigue, or physical function in patients with advanced cancer (palliative- intent). In general, all the studies reported positive findings, but the overall methodological quality was poor. There is currently insufficient evidence for definitive conclusions regarding the 
tolerability, safety, or efficacy of exercise in cancer patients with advanced disease. Given the poorer prognosis and elevated treatment toxicity in this setting, we stress the importance of rigorous $\mathrm{AE}$ and safety monitoring in planned exercise studies is comparable to that required for pharmaceutical intervention trials, in conjunction with appropriate correlative science components. Such an approach will ensure the optimal safety and efficacy of exercise in this unique setting.

\section{Summary}

Research and clinical interest in exercise therapy as a result of a cancer diagnosis have increased significantly over the last decade. The current evidence base provides strong but preliminary evidence that exercise training is a well-tolerated and safe adjunct therapy that can mitigate several common treatment-related side-effects among patients receiving adjuvant therapy for early-stage disease. Results of these "first generation" studies provide a solid platform to launch "second generation" studies that will extend the scope and application of exercise-oncology research to address the major unanswered questions in this emerging field.

\section{Acknowledgments}

Dr. Jones is supported by financial grants NIH CA143254, CA142566, CA138634, CA133895, CA125458, and the Susan and George Beischer Foundation.

\section{References}

Papers of particular interest, published recently, have been highlighted as:

- Of importance

•• Of major importance

1. Morris JN, Heady JA, Raffle PA, et al. Coronary heart-disease and physical activity of work. Lancet. 1953; 265:1111-1120. concl. [PubMed: 13110075]

2. Morris JN, Heady JA, Raffle PA, et al. Coronary heart-disease and physical activity of work. Lancet. 1953; 265:1053-1057. contd. [PubMed: 13110049]

3. Schwartz AL, Winters-Stone K, Gallucci B. Exercise effects on bone mineral density in women with breast cancer receiving adjuvant chemotherapy. Oncol Nurs Forum. 2007; 34:627-633. [PubMed: 17573321]

4. Warburton DE, Nicol CW, Bredin SS. Health benefits of physical activity: the evidence. CMAJ. 2006; 174:801-809. [PubMed: 16534088]

5. Pate RR, Pratt M, Blair SN, et al. Physical activity and public health. A recommendation from the Centers for Disease Control and Prevention and the American College of Sports Medicine. JAMA. 1995; 273:402-407. [PubMed: 7823386]

6. Byers T, Nestle M, McTiernan A, et al. American Cancer Society guidelines on nutrition and physical activity for cancer prevention: reducing the risk of cancer with healthy food choices and physical activity. CA Cancer J Clin. 2002; 52:92-119. [PubMed: 11929008]

7. Jones LW, Peppercorn J. Exercise research: early promise warrants further investment. Lancet Oncol. 2010; 11:408-410. [PubMed: 20434709]

8. Brown JK, Byers T, Doyle C, et al. Nutrition and physical activity during and after cancer treatment: an American Cancer Society guide for informed choices. CA Cancer J Clin. 2003; 53:268-291. [PubMed: 14570227]

9. Winningham ML, MacVicar MG. The effect of aerobic exercise on patient reports of nausea. Oncol Nurs Forum. 1988; 15:447-450. [PubMed: 3399417] 
10. Winningham ML, MacVicar MG, Bondoc M, et al. Effect of aerobic exercise on body weight and composition in patients with breast cancer on adjuvant chemotherapy. Oncol Nurs Forum. 1989; 16:683-689. [PubMed: 2780404]

11. MacVicar MG, Winningham ML, Nickel JL. Effects of aerobic interval training on cancer patients' functional capacity. Nurs Res. 1989; 38:348-351. [PubMed: 2587289]

12. Winningham ML. Walking program for people with cancer. Getting started. Cancer Nurs. 1991; 14:270-276. [PubMed: 1933847]

13. Gianni L, Dombernowsky P, Sledge G, et al. Cardiac function following combination therapy with paclitaxel and doxorubicin: an analysis of 657 women with advanced breast cancer. Ann Oncol. 2001; 12:1067-1073. [PubMed: 11583187]

14. Speck RM, Courneya KS, Masse LC, et al. An update of controlled physical activity trials in cancer survivors: a systematic review and meta-analysis. J Cancer Surviv. 2010; 4:87-100. [PubMed: 20052559]

15. Kolden GG, Strauman TJ, Ward A, et al. A pilot study of group exercise training (GET) for women with primary breast cancer: feasibility and health benefits. Psychooncology. 2002; 11:447456. [PubMed: 12228878]

16•. Jones LW, Eves ND, Courneya KS, et al. Effects of exercise training on antitumor efficacy of doxorubicin in MDA-MB-231 breast cancer xenografts. Clin Cancer Res. 2005; 11:6695-6698. This preclinical study is the first to investigate the potential interaction between exercise and chemotherapy efficacy in mouse model of cancer. [PubMed: 16166449]

$17 \bullet$. Holmes MD, Chen WY, Feskanich D, et al. Physical activity and survival after breast cancer diagnosis. JAMA. 2005; 293:2479-2486. This epidemiological study was the first to show that regular exercise is associated with substantial reductions in cancerspecific and all-cause mortality following a breast cancer diagnosis, relative to inactive women. [PubMed: 15914748]

18•. Courneya KS, Booth CM, Gill S, et al. The Colon Health and Life-Long Exercise Change trial: a randomized trial of the National Cancer Institute of Canada Clinical Trials Group. Curr Oncol. $2008 ; 15: 279-285$. This is the first randomized trial to investigate the effects of exercise training on clinical outcome in any cancer population. [PubMed: 19079628]

19. Segal R, Evans W, Johnson D, et al. Structured exercise improves physical functioning in women with stages I and II breast cancer: results of a randomized controlled trial. J Clin Oncol. 2001; 19:657-665. [PubMed: 11157015]

20. Courneya KS, Segal RJ, Mackey JR, et al. Effects of aerobic and resistance exercise in breast cancer patients receiving adjuvant chemotherapy: a multicenter randomized controlled trial. J Clin Oncol. 2007; 25:4396-4404. [PubMed: 17785708]

21. Meyerhardt JA, Ogino S, Kirkner GJ, et al. Interaction of molecular markers and physical activity on mortality in patients with colon cancer. Clin Cancer Res. 2009; 15:5931-5936. [PubMed: 19723652]

22. Jones LW, Demark-Wahnefried W. Diet, exercise, and complementary therapies after primary treatment for cancer. Lancet Oncol. 2006; 7:1017-1026. [PubMed: 17138223]

23. McNeely ML, Campbell KL, Rowe BH, et al. Effects of exercise on breast cancer patients and survivors: a systematic review and meta-analysis. CMAJ. 2006; 175:34-41. [PubMed: 16818906]

24. Markes M, Brockow T, Resch KL. Exercise for women receiving adjuvant therapy for breast cancer. Cochrane Database Syst Rev. 2006:CD0050.

25. Schmitz KH, Holtzman J, Courneya KS, et al. Controlled physical activity trials in cancer survivors: a systematic review and meta-analysis. Cancer Epidemiol Biomarkers Prev. 2005; 14:1588-1595. [PubMed: 16030088]

26. Friendenreich CM, Courneya KS. Exercise as rehabilitation for cancer patients. Clin J Sport Med. 1996; 6:237-244. [PubMed: 8894336]

27. Stevinson C, Lawlor DA, Fox KR. Exercise interventions for cancer patients: systematic review of controlled trials. Cancer Causes Control. 2004; 15:1035-1056. [PubMed: 15801488]

28. Jones LW, Liang Y, Pituskin EN, et al. Effect of exercise training on cardiorespiratory fitness in patients with cancer: a meta-analysis. J Clin Oncol. submitted.

29-. Jones LW, Eves ND, Haykowsky M, et al. Exercise intolerance in cancer and the role of exercise therapy to reverse dysfunction. Lancet Oncol. 2009; 10:598-605. This paper comprehensively

Curr Treat Options Oncol. Author manuscript; available in PMC 2013 April 08. 
reviews the potential physiologic and molecular mechanisms underlying poor exercise tolerance in cancer patients. It also reviews the efficacy and mechanisms of aerobic training to prevent and/ or treat exercise impairment. [PubMed: 19482248]

30. Myers J, Prakash M, Froelicher V, et al. Exercise capacity and mortality among men referred for exercise testing. N Engl J Med. 2002; 346:793-801. [PubMed: 11893790]

31. Gulati M, Black HR, Shaw LJ, et al. The prognostic value of a nomogram for exercise capacity in women. N Engl J Med. 2005; 353:468-475. [PubMed: 16079370]

32. Ekelund LG, Haskell WL, Johnson JL, et al. Physical fitness as a predictor of cardiovascular mortality in asymptomatic North American men. The Lipid Research Clinics Mortality Follow-up Study. N Engl J Med. 1988; 319:1379-1384. [PubMed: 3185648]

33. Sandvik L, Erikssen J, Thaulow E, et al. Physical fitness as a predictor of mortality among healthy, middle-aged Norwegian men. N Engl J Med. 1993; 328:533-537. [PubMed: 8426620]

34. Erikssen G, Liestol K, Bjornholt J, et al. Changes in physical fitness and changes in mortality. Lancet. 1998; 352:759-762. [PubMed: 9737279]

35. Mentzer SJ, Swanson SJ. Treatment of patients with lung cancer and severe emphysema. Chest. 1999; 116:477S-479S. [PubMed: 10619513]

36. Choong CK, Mahesh B, Patterson GA, et al. Concomitant lung cancer resection and lung volume reduction surgery. Thorac Surg Clin. 2009; 19:209-216. [PubMed: 19662963]

37. Colice GL, Shafazand S, Griffin JP, et al. Physiologic evaluation of the patient with lung cancer being considered for resectional surgery: ACCP evidenced-based clinical practice guidelines (2nd edition). Chest. 2007; 132:161S-177S. [PubMed: 17873167]

38. Torchio R, Guglielmo M, Giardino R, et al. Exercise ventilatory inefficiency and mortality in patients with chronic obstructive pulmonary disease under-going surgery for non-small-cell lung cancer. Eur J Cardiothorac Surg.

39. Kasikcioglu E, Toker A, Tanju S, et al. Oxygen uptake kinetics during cardiopulmonary exercise testing and postoperative complications in patients with lung cancer. Lung Cancer. 2009; 66:8588. [PubMed: 19185383]

40. Bobbio A, Chetta A, Internullo E, et al. Exercise capacity assessment in patients undergoing lung resection. Eur J Cardiothorac Surg. 2009; 35:419-422. [PubMed: 19138529]

41. Brunelli A, Belardinelli R, Refai M, et al. Peak oxygen consumption during cardiopulmonary exercise test improves risk stratification in candidates to major lung resection. Chest. 2009; 135:1260-1267. [PubMed: 19029436]

42••. Jones LW, Watson D, Herndon JE II, et al. Peak oxygen consumption and long-term all-cause mortality in non-small cell lung cancer. Cancer. in press. Peak oxygen consumption $\left(\mathrm{VO}_{2 \text { peak }}\right)$ is a strong predictor of cardiovascular and all-cause mortality in a broad range of clinical populations but this is the first to show that $\mathrm{VO}_{2 \text { peak }}$ predicts mortality following a diagnosis of cancer.

43. Jones LW, Peddle CJ, Eves ND, et al. Effects of presurgical exercise training on cardiorespiratory fitness among patients undergoing thoracic surgery for malignant lung lesions. Cancer. 2007; 110:590-598. [PubMed: 17582629]

44. Bobbio A, Chetta A, Ampollini L, et al. Preoperative pulmonary rehabilitation in patients undergoing lung resection for non-small cell lung cancer. Eur J Cardiothorac Surg. 2008; 33:9598. [PubMed: 18006327]

45. Demark-Wahnefried W, George SL, Switzer BR, et al. Overcoming challenges in designing and implementing a phase II randomized controlled trial using a presurgical model to test a dietary intervention in prostate cancer. Clin Trials. 2008; 5:262-272. [PubMed: 18559416]

46. Lin DW, Neuhouser ML, Schenk JM, et al. Low-fat, low-glycemic load diet and gene expression in human prostate epithelium: a feasibility study of using cDNA microarrays to assess the response to dietary intervention in target tissues. Cancer Epidemiol Biomarkers Prev. 2007; 16:2150-2154. [PubMed: 17932364]

47. Demark-Wahnefried W, Polascik TJ, George SL, et al. Flaxseed supplementation (not dietary fat restriction) reduces prostate cancer proliferation rates in men presurgery. Cancer Epidemiol Biomarkers Prev. 2008; 17:3577-3587. [PubMed: 19064574] 
48. Jones LW, Eves ND, Peterson BL, et al. Safety and feasibility of aerobic training on cardiopulmonary function and quality of life in postsurgical nonsmall cell lung cancer patients: a pilot study. Cancer. 2008; 113:3430-3439. [PubMed: 18988290]

49. Segal RJ, Reid RD, Courneya KS, et al. Resistance exercise in men receiving androgen deprivation therapy for prostate cancer. J Clin Oncol. 2003; 21:1653-1659. [PubMed: 12721238]

50. Galvao DA, Newton RU. Review of exercise intervention studies in cancer patients. J Clin Oncol. 2005; 23:899-909. [PubMed: 15681536]

51. Courneya KS, Sellar CM, Stevinson C, et al. Randomized controlled trial of the effects of aerobic exercise on physical functioning and quality of life in lymphoma patients. J Clin Oncol. 2009; 27:4605-4612. [PubMed: 19687337]

52. Windsor PM, Nicol KF, Potter J. A randomized, controlled trial of aerobic exercise for treatmentrelated fatigue in men receiving radical external beam radiotherapy for localized prostate carcinoma. Cancer. 2004; 101:550-557. [PubMed: 15274068]

53. Courneya KS, Jones LW, Peddle CJ, et al. Effects of aerobic exercise training in anemic cancer patients receiving darbepoetin alfa: a randomized controlled trial. Oncologist. 2008; 13:10121020. [PubMed: 18779540]

54. Adamsen L, Quist M, Andersen C, et al. Effect of a multimodal high intensity exercise intervention in cancer patients undergoing chemotherapy: randomised controlled trial. BMJ. 2009; 339:b3410. [PubMed: 19826172]

55. Chen HX, Cleck JN. Adverse effects of anticancer agents that target the VEGF pathway. Nat Rev Clin Oncol. 2009; 6:465-477. [PubMed: 19581909]

56. Kamba T, McDonald DM. Mechanisms of adverse effects of anti-VEGF therapy for cancer. Br J Cancer. 2007; 96:1788-1795. [PubMed: 17519900]

57. Jones LW, Haykowsky MJ, Swartz JJ, et al. Early breast cancer therapy and cardiovascular injury. J Am Coll Cardiol. 2007; 50:1435-1441. [PubMed: 17919562]

58. Yeh ET, Tong AT, Lenihan DJ, et al. Cardiovascular complications of cancer therapy: diagnosis, pathogenesis, and management. Circulation. 2004; 109:3122-3131. [PubMed: 15226229]

59. Giordano SH, Kuo YF, Freeman JL, et al. Risk of cardiac death after adjuvant radiotherapy for breast cancer. J Natl Cancer Inst. 2005; 97:419-424. [PubMed: 15770005]

60. Harris EE, Correa C, Hwang WT, et al. Late cardiac mortality and morbidity in early-stage breast cancer patients after breast-conservation treatment. J Clin Oncol. 2006; 24:4100-4106. [PubMed: 16908933]

61. Chien AJ, Rugo HS. The cardiac safety of trastuzumab in the treatment of breast cancer. Expert Opin Drug Saf. 9:335-346. [PubMed: 20175700]

62. Hydock DS, Wonders KY, Schneider CM, et al. Voluntary wheel running in rats receiving doxorubicin: effects on running activity and cardiac myosin heavy chain. Anticancer Res. 2009; 29:4401-4407. [PubMed: 20032385]

63. Wonders KY, Hydock DS, Schneider CM, et al. Acute exercise protects against doxorubicin cardiotoxicity. Integr Cancer Ther. 2008; 7:147-154. [PubMed: 18815146]

64. Hydock DS, Lien CY, Schneider CM, et al. Exercise preconditioning protects against doxorubicininduced cardiac dysfunction. Med Sci Sports Exerc. 2008; 40:808-817. [PubMed: 18408619]

65. Chicco AJ, Hydock DS, Schneider CM, et al. Lowintensity exercise training during doxorubicin treatment protects against cardiotoxicity. J Appl Physiol. 2006; 100:519-527. [PubMed: 16210442]

66. Chicco AJ, Schneider CM, Hayward R. Voluntary exercise protects against acute doxorubicin cardiotoxicity in the isolated perfused rat heart. Am J Physiol Regul Integr Comp Physiol. 2005; 289:R424-R431. [PubMed: 15845878]

67•. Haykowsky MJ, Mackey JR, Thompson RB, et al. Adjuvant trastuzumab induces ventricular remodeling despite aerobic exercise training. Clin Cancer Res. 2009; 15:4963-4967. This is the first study to investigate the effects of exercise training on cardiac function in cancer patients undergoing HER-2 targeted therapy for early-stage breast cancer. [PubMed: 19622583]

68. Courneya KS, Mackey JR, Bell GJ, et al. Randomized controlled trial of exercise training in postmenopausal breast cancer survivors: cardiopulmonary and quality of life outcomes. J Clin Oncol. 2003; 21:1660-1668. [PubMed: 12721239] 
69. Jemal A, Siegel R, Ward E, et al. Cancer statistics, 2009. CA Cancer J Clin. 2009; 59:225-249. [PubMed: 19474385]

70. Ganz PA. Harnessing personalised medicine to prevent late effects. Lancet Oncol. 11:7-9. [PubMed: 19931488]

71. Ganz PA, Hahn EE. Implementing a survivorship care plan for patients with breast cancer. J Clin Oncol. 2008; 26:759-767. [PubMed: 18258984]

72. Jones LW, Haykowsky M, Pituskin EN, et al. Cardiovascular reserve and risk profile of postmenopausal women after chemoendocrine therapy for hormone receptor-positive operable breast cancer. Oncologist. 2007; 12:1156-1164. [PubMed: 17962609]

73. Jones LW, Haykowsky M, Peddle CJ, et al. Cardiovascular risk profile of patients with HER2/ neu-positive breast cancer treated with anthracycline- taxane-containing adjuvant chemotherapy and/or trastuzumab. Cancer Epidemiol Biomarkers Prev. 2007; 16:1026-1031. [PubMed: 17507633]

74. Jones LW, Eves ND, Mackey JR, et al. Safety and feasibility of cardiopulmonary exercise testing in patients with advanced cancer. Lung Cancer. 2007; 55:225-232. [PubMed: 17113185]

75. Jones LW, Eves ND, Mackey JR, et al. Systemic inflammation, cardiorespiratory fitness, and quality of life in patients with advanced non-small cell lung cancer. J Thorac Oncol. 2008; 3:194195. [PubMed: 18303444]

76. Herrero F, Balmer J, San Juan AF, et al. Is cardiorespiratory fitness related to quality of life in survivors of breast cancer? J Strength Cond Res. 2006; 20:535-540. [PubMed: 16977706]

77. Jones LW, Friedman AH, West MJ, et al. Quantitative assessment of cardiorespiratory fitness, skeletal muscle function, and body composition in adults with primary malignant glioma. Cancer. 116:695-704. [PubMed: 20029975]

78. Jones LW, Eves ND, Kraus WE, et al. The lung cancer exercise training study: a randomized trial of aerobic training, resistance training, or both in postsurgical lung cancer patients: rationale and design. BMC Cancer. 10:155. [PubMed: 20409311]

79. Jones LW, Douglas PS, Eves ND, et al. Rationale and design of the exercise intensity trial (EXCITE): a randomized trial comparing the effects of moderate versus moderate to high-intensity aerobic training in women with operable breast cancer. BMC Cancer. submitted.

80. Galvao DA, Spry N, Taaffe DR, et al. A randomized controlled trial of an exercise intervention targeting cardiovascular and metabolic risk factors for prostate cancer patients from the RADAR trial. BMC Cancer. 2009; 9:419. [PubMed: 19951446]

81. Ciolac EG, Bocchi EA, Bortolotto LA, et al. Effects of high-intensity aerobic interval training vs. moderate exercise on hemodynamic, metabolic and neuro-humoral abnormalities of young normotensive women at high familial risk for hypertension. Hypertens Res.

82. Tjonna AE, Lee SJ, Rognmo O, et al. Aerobic interval training versus continuous moderate exercise as a treatment for the metabolic syndrome: a pilot study. Circulation. 2008; 118:346-354. [PubMed: 18606913]

83. Tjonna AE, Stolen TO, Bye A, et al. Aerobic interval training reduces cardiovascular risk factors more than a multitreatment approach in overweight adolescents. Clin Sci (Lond). 2009; 116:317326. [PubMed: 18673303]

84. Ibrahim EM, Al-Homaidh A. Physical activity and survival after breast cancer diagnosis: metaanalysis of published studies. Med Oncol.

85. Meyerhardt JA, Giovannucci EL, Ogino S, et al. Physical activity and male colorectal cancer survival. Arch Intern Med. 2009; 169:2102-2108. [PubMed: 20008694]

86. Meyerhardt JA, Giovannucci EL, Holmes MD, et al. Physical activity and survival after colorectal cancer diagnosis. J Clin Oncol. 2006; 24:3527-3534. [PubMed: 16822844]

87. Meyerhardt JA, Heseltine D, Niedzwiecki D, et al. Impact of physical activity on cancer recurrence and survival in patients with stage III colon cancer: findings from CALGB 89803. J Clin Oncol. 2006; 24:3535-3541. [PubMed: 16822843]

88. Holick CN, Newcomb PA, Trentham-Dietz A, et al. Physical activity and survival after diagnosis of invasive breast cancer. Cancer Epidemiol Biomarkers Prev. 2008; 17:379-386. [PubMed: 18250341] 
89. Irwin ML, Smith AW, McTiernan A, et al. Influence of pre- and postdiagnosis physical activity on mortality in breast cancer survivors: the health, eating, activity, and lifestyle study. J Clin Oncol. 2008; 26:3958-3964. [PubMed: 18711185]

90. Sternfeld B, Weltzien E, Quesenberry CP Jr, et al. Physical activity and risk of recurrence and mortality in breast cancer survivors: findings from the LACE study. Cancer Epidemiol Biomarkers Prev. 2009; 18:87-95. [PubMed: 19124485]

91. Pierce JP, Stefanick ML, Flatt SW, et al. Greater survival after breast cancer in physically active women with high vegetable-fruit intake regardless of obesity. J Clin Oncol. 2007; 25:2345-2351. [PubMed: 17557947]

92. Dal Maso L, Zucchetto A, Talamini R, et al. Effect of obesity and other lifestyle factors on mortality in women with breast cancer. Int J Cancer. 2008; 123:2188-2194. [PubMed: 18711698]

93. Ballard-Barbash R, Hunsberger S, Alciati MH, et al. Physical activity, weight control, and breast cancer risk and survival: clinical trial rationale and design considerations. J Natl Cancer Inst. 2009; 101:630-643. [PubMed: 19401543]

94-. Jones LW, Eves ND, Haykowsky M, et al. Cardiorespiratory exercise testing in clinical oncology research: systematic review and practice recommendations. Lancet Oncol. 2008; 9:757-765. The use of cardiorespiratory fitness testing following a cancer diagnosis has markedly increased over the past decade. To this end, this paper provides cardiorespiratory fitness testing guidelines for scientists and clinicians performing exercise testing in cancer patients. [PubMed: 18672211]

95. Lowe SS, Watanabe SM, Courneya KS. Physical activity as a supportive care intervention in palliative cancer patients: a systematic review. J Support Oncol. 2009; 7:27-34. [PubMed: 19278175] 

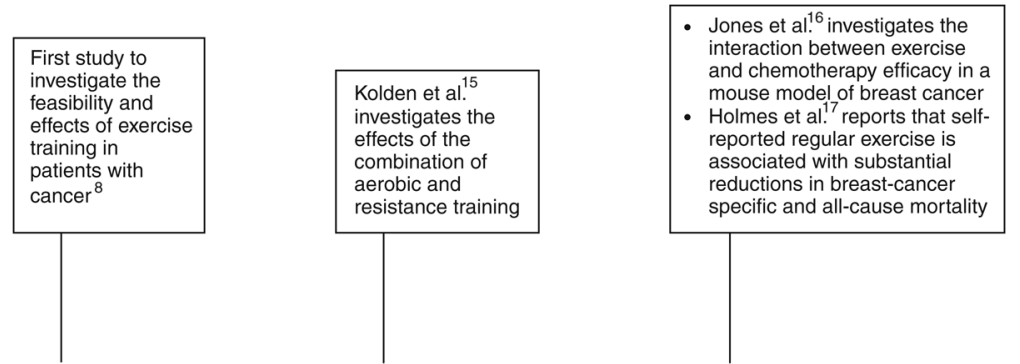

First randomized trial is launched by the National Cancer Institute of Canada to investigate the effects of exercise on disease-free survival in patients with operable colon cancer following the

completion of adjuvant therapy ${ }^{18}$

combination of

aerobic and

resistance training

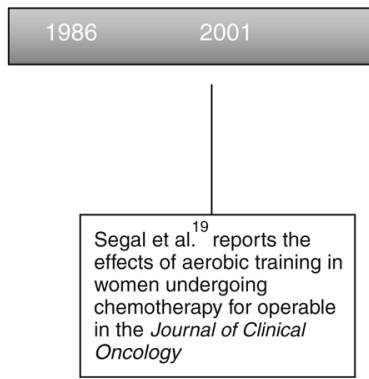

2002

2003

2005

2007

\begin{tabular}{|l|}
\hline The American Cancer Society \\
convenes a group of experts \\
to create exercise \\
recommendations for cancer \\
patients in $C A$ : $A$ Cancer \\
Journal for Clinicians
\end{tabular}

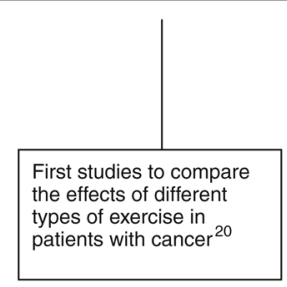

2008

2009

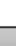

Figure 1.

Exercise-oncology research timeline 


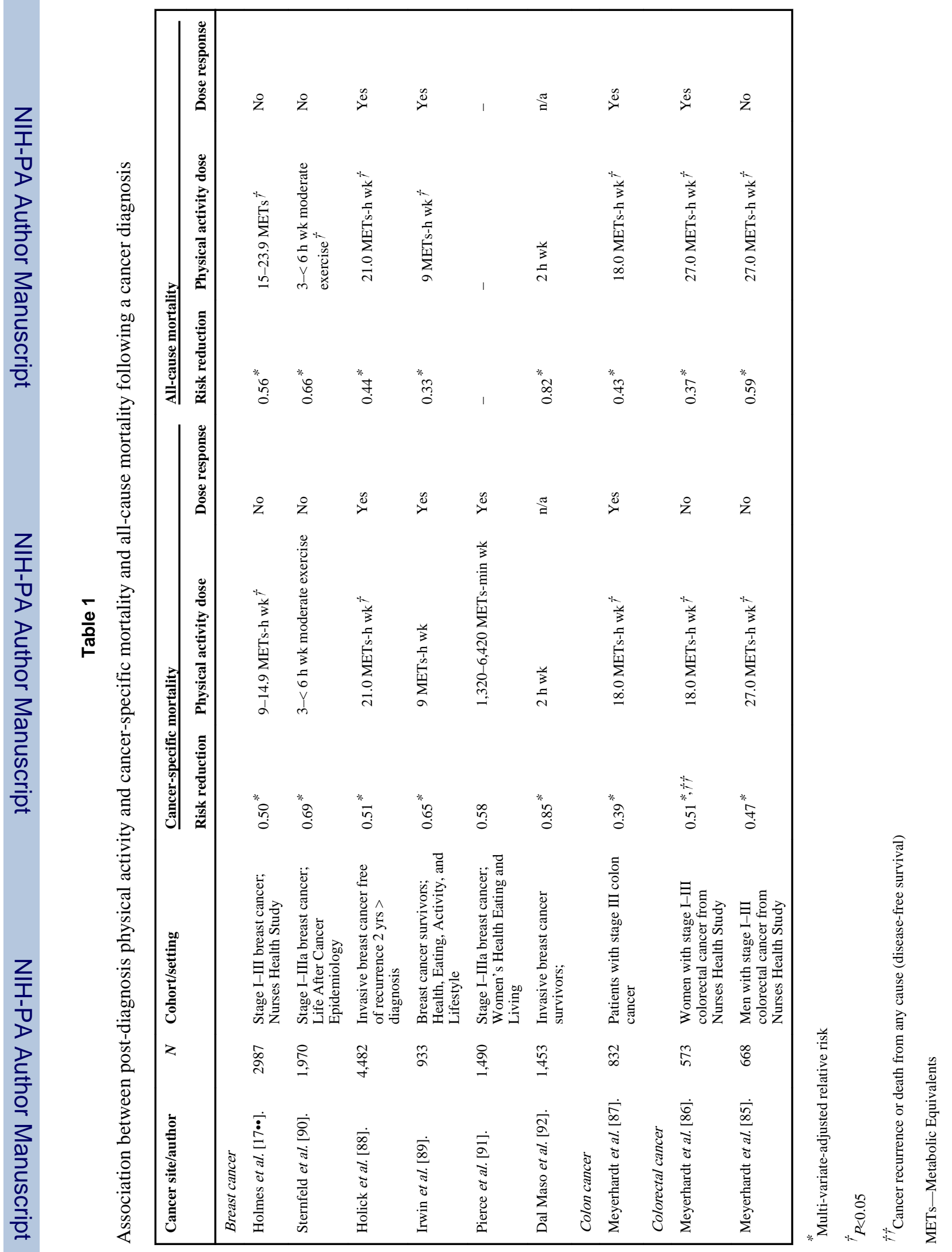

Curr Treat Options Oncol. Author manuscript; available in PMC 2013 April 08. 